\title{
Microstructure and Hardness Evolution in Haynes 282 Nickel-Based Superalloy During Multi-variant Aging Heat Treatment
}

\author{
Adelajda Polkowska, Wojciech Polkowski, Małgorzata Warmuzek, Natalia Cieśla, Grzegorz Włoch, Dariusz Zasada, and Robert M. Purgert
}

(Submitted October 5, 2018; in revised form January 5, 2019; published online January 23, 2019)

\begin{abstract}
In this paper, the effect of applied multi-variant heat treatment on microstructure, phase composition and mechanical response of Haynes 282 nickel-based superalloy was investigated. For this reason, temperatures of both stages of standard two-stage aging treatment (i.e., $1010{ }^{\circ} \mathrm{C} / 2 \mathrm{~h}+780{ }^{\circ} \mathrm{C} / 8 \mathrm{~h}$ ) were extended to 900 $1100{ }^{\circ} \mathrm{C} / 2 \mathrm{~h}$ and $680-880{ }^{\circ} \mathrm{C} / 8 \mathrm{~h}$ ranges, respectively. Consequently, 30 different variants of heat treatment were applied. The microstructural features of heat-treated samples were investigated by means of light microscopy and SEM/EDS methods, while mechanical properties were examined via microhardness measurements. It was found that by using various combinations of temperatures of the first and second stage of aging, the room temperature hardness of Haynes 282 alloy can be decreased by $\sim 100 \mathrm{HV}$ units or increased by up to $25 \mathrm{HV}$ units as compared to that of the alloy subjected to the standard heat treatment schedule. The mechanical response of the alloy is determined by a complex structural evolution involving the secondary precipitation of $\gamma^{\prime}, M_{23} C_{6}$ and $M_{6} C$ phases, as well as their interaction with the fec $\gamma$ matrix.
\end{abstract}

Keywords characterization, heat treatment, microscopy, microstructure, nickel superalloys

\section{Introduction}

Recent global market analyses and forecasts point toward the irreplaceability of nickel superalloys in the most crucial economic sectors that include defense, energy, marine, aerospace industries and other applications where high performance and reliable materials are required (Ref 1). Nickel-based superalloys are widely used in extremely high-temperature load-bearing applications which are far beyond applicability of any other alloys. Nevertheless, a continuous development of new superalloys is taking place, in order to keep up with a worldwide need to increase the efficiency of power units and plants. One such example is Haynes 282 superalloy, which was

This article is an invited submission to JMEP selected from presentations at the 73rd World Foundry Congress and has been expanded from the original presentation. 73WFC was held in Krakow, Poland, September 23-27, 2018, and was organized by the World Foundry Organization and Polish Foundrymen's Association.

Adelajda Polkowska, Wojciech Polkowski, and Malgorzata Warmuzek, Foundry Research Institute, Zakopiańska 73 Str., 30-418 Kraków, Poland; Natalia Cieśla, Faculty of Materials Science and Ceramics, AGH University of Science and Technology, Mickiewicza 30 Av, 30-059 Kraków, Poland; Grzegorz Wloch, Faculty of Non-Ferrous Metals, AGH University of Science and Technology, Mickiewicza 30 Av, 30-059 Kraków, Poland; Dariusz Zasada, Faculty of Advanced Technologies and Chemistry, Military University of Technology, Kaliskiego 2 Str, 01-476 Warsaw, Poland; and Robert M. Purgert, Energy Industries of Ohio, 6100 Oak Tree Blvd, Cleveland, $\mathrm{OH}$ 44131. Contact e-mail: adelajda.polkowska@iod.krakow.pl.

designed and introduced to overcome temperature limitations of Inconel 718 and Waspaloy in gas turbine engines (Ref 2). Nowadays, the increased working temperature limit ( $\sim 800{ }^{\circ} \mathrm{C}$ ) of Haynes 282 alloy makes it also one of the main candidates for applications in advanced ultra-supercritical power plants (Ref 3$)$.

Haynes 282 is classified as $\gamma^{\prime}$-strengthened wrought superalloy (but, it is also under consideration as a cast alloy for fabrication of casings and thin-walled components (Ref 4, 5)). Its mechanical properties are controlled by the heat treatment containing the solutionizing followed by aging processes. The standard heat treatment procedure includes a solution treatment at $1121-1149{ }^{\circ} \mathrm{C}$ and two-stage age-hardening treatment $\left(1010{ }^{\circ} \mathrm{C} / 2 \mathrm{~h}+780{ }^{\circ} \mathrm{C} / 8 \mathrm{~h}\right)$ needed to put the alloy into the high-strength state. The main role of solution treatment is to dissolve $\gamma^{\prime}$ precipitates and secondary carbides and to form a supersaturated solid solution. The subsequent two-stage aging is performed to precipitate and stabilize carbides (this first stage is also called "stabilization"), and to ensure the precipitation of $\gamma^{\prime}$ (in the second stage). Consequently, after the full cycle of heat treatment, the microstructure of Haynes 282 includes (Ti,Mo)-based $\mathrm{MC}$ and $\mathrm{Cr}$-rich $\mathrm{M}_{23} \mathrm{C}_{6}$ carbides distributed both along grain boundaries and inside grains' volume, and spherical $\gamma^{\prime}$ particles with a typical size of $20 \mathrm{~nm}(\operatorname{Ref} 6)$. In addition, recent studies by Osoba et al. (Ref 7) clearly indicated the presence of $\mathrm{M}_{6} \mathrm{C}$ type carbides after the standard heat treatment. However, as it was theoretically and experimentally documented (Ref 8), the evolution of phase composition obviously depends on applied temperature of heat treatment throughout affecting the phase equilibria of the system. Therefore, the impact of heat treatment parameters (temperature, time) on the microstructure and mechanical properties of Haynes 282 is still under investigation. The results presented in recently published papers point toward a possibility of a further improvement of mechanical properties of Haynes 282 alloy via tailoring the heat treatment conditions. For example, Joseph et al. (Ref 9) reported that lowering temperature of the first 
aging stage $\left(1010{ }^{\circ} \mathrm{C} \rightarrow 996^{\circ} \mathrm{C}\right)$ results in a final bimodal $\gamma^{\prime}$ distribution and grain boundaries decorated by discrete carbides. Consequently, the material was characterized by improved room temperature ductility and simultaneously not decreased strength as compared to the counterpart subjected to the standard heat treatment procedure. Haas et al. (Ref 10) used a in situ small- and wide-angle $\mathrm{x}$-ray scattering (SAXS/WAXS) approach to correlate time-dependent precipitate evolution with Vickers hardness of Haynes 282, during a one-stage aging treatment at $600-1000{ }^{\circ} \mathrm{C}$. They found that a peak strengthening (as the effect of a superposition of $\gamma^{\prime}$ precipitate, solid solution strengthening and carbide strengthening components) takes place during the stabilizing heat treatment carried out at temperatures between 780 and $900{ }^{\circ} \mathrm{C}$.

The main purpose of the present work is to investigate the microstructural evolution and accompanied mechanical response of Haynes 282 alloy under a complex heat treatment scheme extending already examined temperature ranges. Additionally, the standard heat treatment was applied for the sake of comparison.

\section{Materials and Methods}

The material investigated was commercial Haynes 282 alloy in the form of 0.062 " $(1.6 \mathrm{~mm})$ sheet, in the solution-annealed condition, as provided by Haynes International (Kokomo,
Indiana, USA) company. The nominal chemical composition of the alloy is listed in Table 1 .

Small samples of $5 \times 5 \times 1.6 \mathrm{~mm}^{3}$ were cut off from the provided solution-annealed sheet and then subjected to heat treatment (age hardening) experiments. The heat treatments were performed in a laboratory induction furnace, in air atmosphere. The samples were water-quenched after removing from the furnace, every time. Temperatures of both stages of the standard two-stage aging treatment (i.e., $1010{ }^{\circ} \mathrm{C} /$ $2 \mathrm{~h}+780{ }^{\circ} \mathrm{C} / 8 \mathrm{~h}$ ) were extended to $900-1100{ }^{\circ} \mathrm{C} / 2 \mathrm{~h}$ and $680-880{ }^{\circ} \mathrm{C} / 8 \mathrm{~h}$ ranges, respectively (Fig. $1 \mathrm{a}$ and $\mathrm{b}$ ). The full list of annealing conditions applied in 30 different heat treatment experiments (performed under various temperatures of the first and second stages of aging) is presented in Table 2.

The heat-treated samples were subjected to a microstructural characterization by means of light microscopy (LM) (Carl Zeiss Axio Observer ZM10) and scanning electron microscopy (FEI $\mathrm{Scios}^{\mathrm{TM}}$ field emission gun scanning electron microscope-FEG-SEM) coupled with energy-dispersive x-ray spectroscopy (EDS). The cross-sectioned specimens were prepared by mechanical grinding using $\mathrm{SiC}$ papers (up to 2000 grit) followed by polishing with $3-0.1-\mu \mathrm{m}$ diamond suspensions and $0.1-\mu \mathrm{m}$ silica suspension. The microstructural features were revealed by chemical etching with the Aqua regia reagent. Vickers microhardness measurements were performed on a Shimadzu HMV-G tester by using a 200-g load and 10-s dwell time. Indentations were made at ten randomly selected sites of

Table 1 The nominal composition of Haynes 282 superalloy (Ref 2)

\begin{tabular}{lllllllllll}
\hline \multicolumn{10}{c}{ Chemical composition, wt.\% } \\
\hline $\mathbf{N i}$ & $\mathbf{C r}$ & $\mathbf{C o}$ & $\mathbf{M o}$ & $\mathbf{T i}$ & $\mathbf{A l}$ & $\mathbf{F e}$ & $\mathbf{M n}$ & $\mathbf{S i}$ & $\mathbf{C}$ & $\mathbf{B}$ \\
\hline bal. & 20 & 10 & 8.5 & 2.1 & 1.5 & $\max .1 .5$ & $\max .0 .3$ & $\max .0 .15$ & 0.06 & 0.005 \\
\hline
\end{tabular}

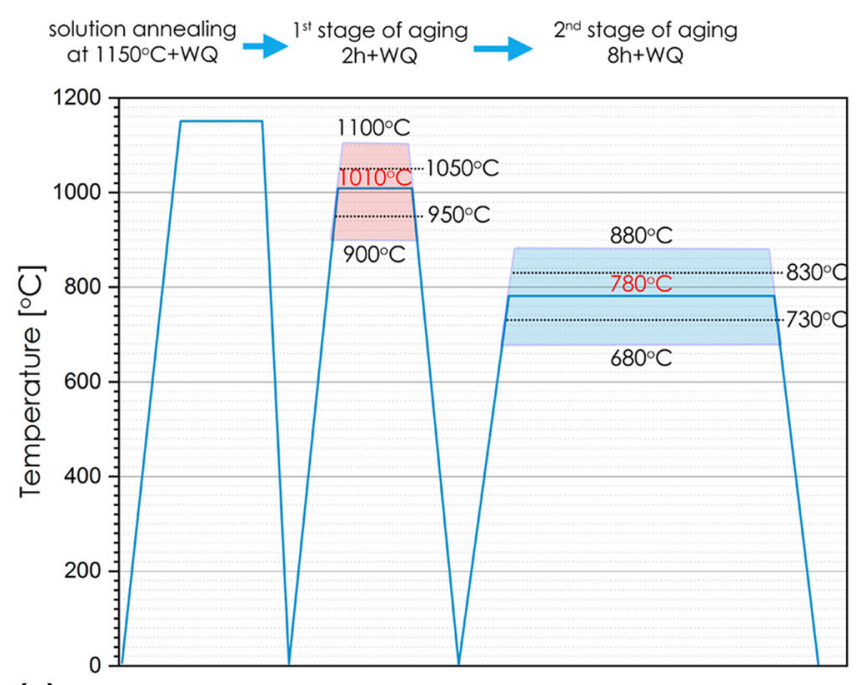

(a)

time

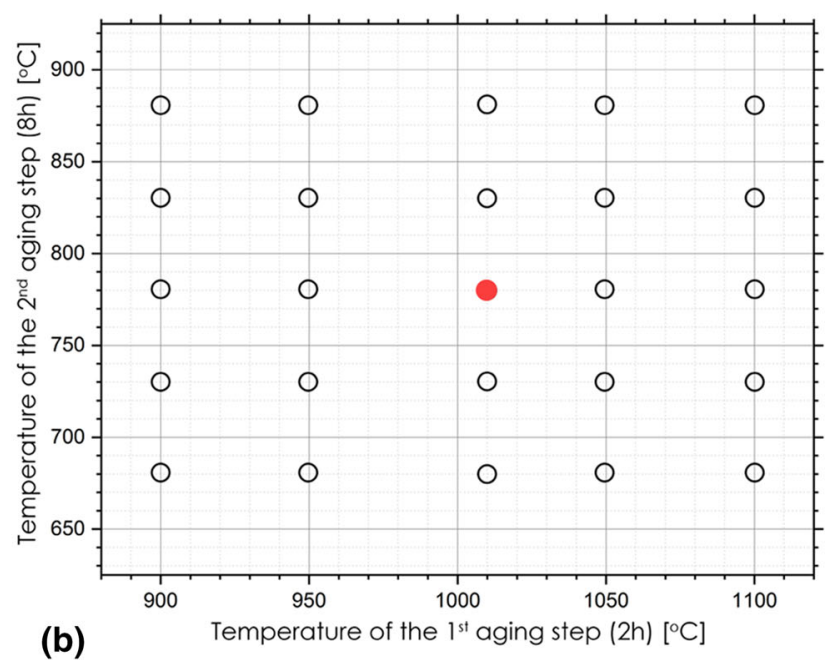

(b)

Fig. 1 Temperature profiles of the applied heat treatments. Temperatures of the standard heat treatment are marked with red color. Temperatures of both stages of the standard two-stage aging treatment (i.e., $1010{ }^{\circ} \mathrm{C} / 2 \mathrm{~h}+780{ }^{\circ} \mathrm{C} / 8 \mathrm{~h}$ ) were extended to $900-1100{ }^{\circ} \mathrm{C} / 2 \mathrm{~h}$ and $680-880{ }^{\circ} \mathrm{C} / 8 \mathrm{~h}$ ranges, respectively (a) giving 25 different variants (b) 
Table 2 The list of annealing conditions (temperatures of the first and second stage of aging) applied in 30 different heat treatment experiments

\begin{tabular}{|c|c|c|c|c|c|c|c|c|}
\hline No. & $\begin{array}{l}T \text { of the first stage } \\
\text { of aging }(2 \mathrm{~h}),{ }^{\circ} \mathrm{C}\end{array}$ & $\begin{array}{c}T \text { of the second } \\
\text { stage of aging } \\
(8 \mathrm{~h}),{ }^{\circ} \mathrm{C}\end{array}$ & No. & $\begin{array}{l}T \text { of the first stage } \\
\text { of aging }(2 \mathrm{~h}),{ }^{\circ} \mathrm{C}\end{array}$ & $\begin{array}{c}T \text { of the second } \\
\text { stage of aging } \\
(8 \mathrm{~h}),{ }^{\circ} \mathrm{C}\end{array}$ & No. & $\begin{array}{l}T \text { of the first stage } \\
\text { of aging }(2 \mathrm{~h}),{ }^{\circ} \mathrm{C}\end{array}$ & $\begin{array}{l}T \text { of the second } \\
\text { stage of aging } \\
\quad(8 \mathrm{~h}),{ }^{\circ} \mathrm{C}\end{array}$ \\
\hline 1 & 900 & $\ldots$ & 11 & 900 & 730 & 21 & 900 & 830 \\
\hline 2 & 950 & $\ldots$ & 12 & 950 & 730 & 22 & 950 & 830 \\
\hline 3 & 1010 & $\ldots$ & 13 & 1010 & 730 & 23 & 1010 & 830 \\
\hline 4 & 1050 & $\begin{array}{l}\cdots \\
\ldots\end{array}$ & 14 & 1050 & 730 & 24 & 1050 & 830 \\
\hline 5 & 1100 & $\ldots$ & 15 & 1100 & 730 & 25 & 1100 & 830 \\
\hline 6 & 900 & 680 & 16 & 900 & 780 & 26 & 900 & 880 \\
\hline 7 & 950 & 680 & 17 & 950 & 780 & 27 & 950 & 880 \\
\hline 8 & 1010 & 680 & 18 & 1010 & 780 & 28 & 1010 & 880 \\
\hline 9 & 1050 & 680 & 19 & 1050 & 780 & 29 & 1050 & 880 \\
\hline 10 & 1100 & 680 & 20 & 1100 & 780 & 30 & 1100 & 880 \\
\hline
\end{tabular}
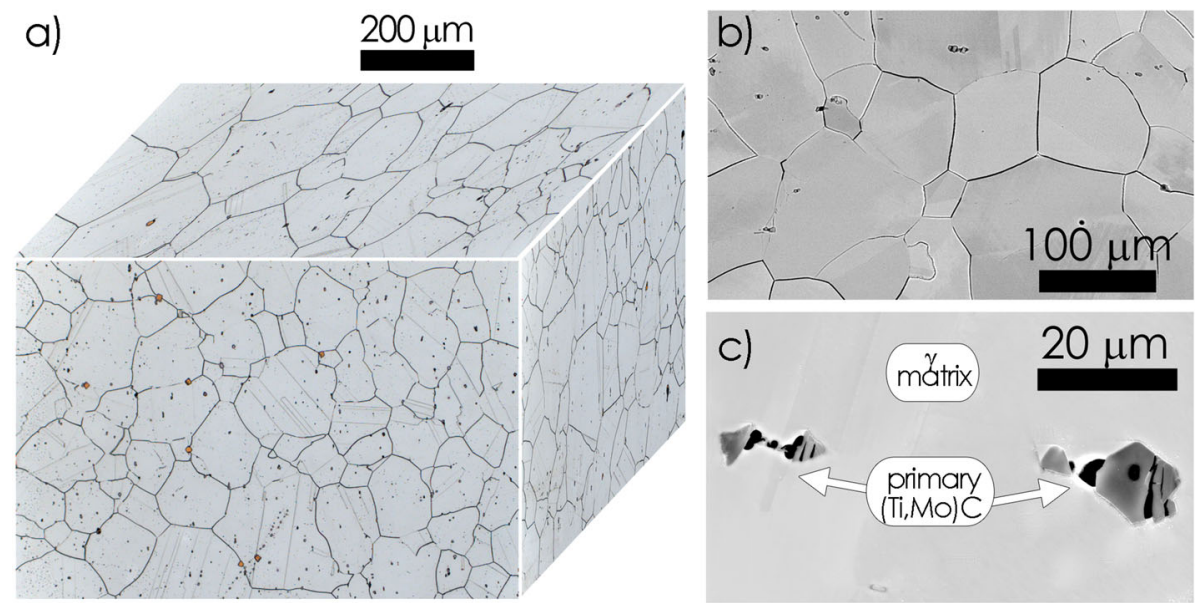

Fig. 2 Microstructure of Haynes 282 alloy in the as-received (solution-annealed) condition: pseudo-3D LM image of Haynes 282 microstructure (a); FEG-SEM images showing a lack of grain boundary precipitation (b) and a presence of blocky-like primary (Ti, Mo)-rich $\mathrm{MC}$ carbides inside grains volume

each cross-sectioned sample, and then average values were calculated.

\section{Results and Discussion}

\subsection{Standard Heat Treatment}

Haynes 282 alloy in the as-received (solution-annealed) condition was characterized by the ASTM grain size of 4-4.5 (corresponding average grain diameter of $65-90 \mu \mathrm{m}$ ) of the austenitic $\gamma$ solid solution matrix (Fig. 2a). Since the solutionizing treatment was performed at temperature above the solvus of $\mathrm{M}_{23} \mathrm{C}_{6}$ carbides, both grain boundaries and grain interiors were free of secondary precipitation (Fig. 2b). However, large, blocky-like primary ( $\mathrm{Ti}, \mathrm{Mo}$ )-rich $\mathrm{MC}$ carbides were observed inside grains volume (Fig. 2c). The Vickers hardness of the material in the as-received state was $250 \pm 8 \mathrm{HV}$.

As it was expected, the standard two-stage heat treatment $\left(1010{ }^{\circ} \mathrm{C} / 2 \mathrm{~h}+780{ }^{\circ} \mathrm{C} / 8 \mathrm{~h}\right)$ resulted in an extensive structural evolution dominated by a massive precipitation. After the first stage of aging $\left(1010^{\circ} \mathrm{C} / 2 \mathrm{~h}\right)$, grain interiors seemed to be free of the $\gamma^{\prime}$ precipitates, while grain boundaries exhibited a presence of discrete $\mathrm{Cr}$-rich $\mathrm{M}_{23} \mathrm{C}_{6}$ carbide precipitates (Fig. 3a). Furthermore, aside from the primary MC, few intragranular and intergranular Mo-enriched $\mathrm{M}_{6} \mathrm{C}$ carbides were also detected (Fig. 3a). Due to a higher $\mathrm{Z}$ value of molybdenum than chromium, $\mathrm{M}_{6} \mathrm{C}$ appears to be brighter than $\mathrm{M}_{23} \mathrm{C}_{6}$ in the SEM/BSE images. After the first stage of aging, only a slight increase in hardness was measured as compared to the solutionized material $(250 \rightarrow 263 \mathrm{HV})$.

The second stage of standard aging treatment $\left(780{ }^{\circ} \mathrm{C} / 8 \mathrm{~h}\right)$ (Fig. 3b, c) led to the precipitation of very fine (tens of nanometers in size) $\gamma^{\prime}$ particles as well as altered the carbides size and morphology. It is found that $\mathrm{M}_{23} \mathrm{C}_{6}$ secondary carbides located along grain boundaries underwent significant coarsening as compared to that presented in the alloy after the first stage of aging. Additionally, some effects of the reaction taken at the primary $\mathrm{MC} / \gamma$ solid solution interface leading to the formation of Mo-enriched outer area and growth of new $\mathrm{M}_{6} \mathrm{C}$ carbides as interfacial products (Fig. 4) were also noted.

The reactions between primary carbides and matrix leading to the formation of either $\mathrm{M}_{23} \mathrm{C}_{6}$ or $\mathrm{M}_{6} \mathrm{C}$, involving also simultaneous precipitation of $\gamma^{\prime}$ can be written as (Ref 11): 

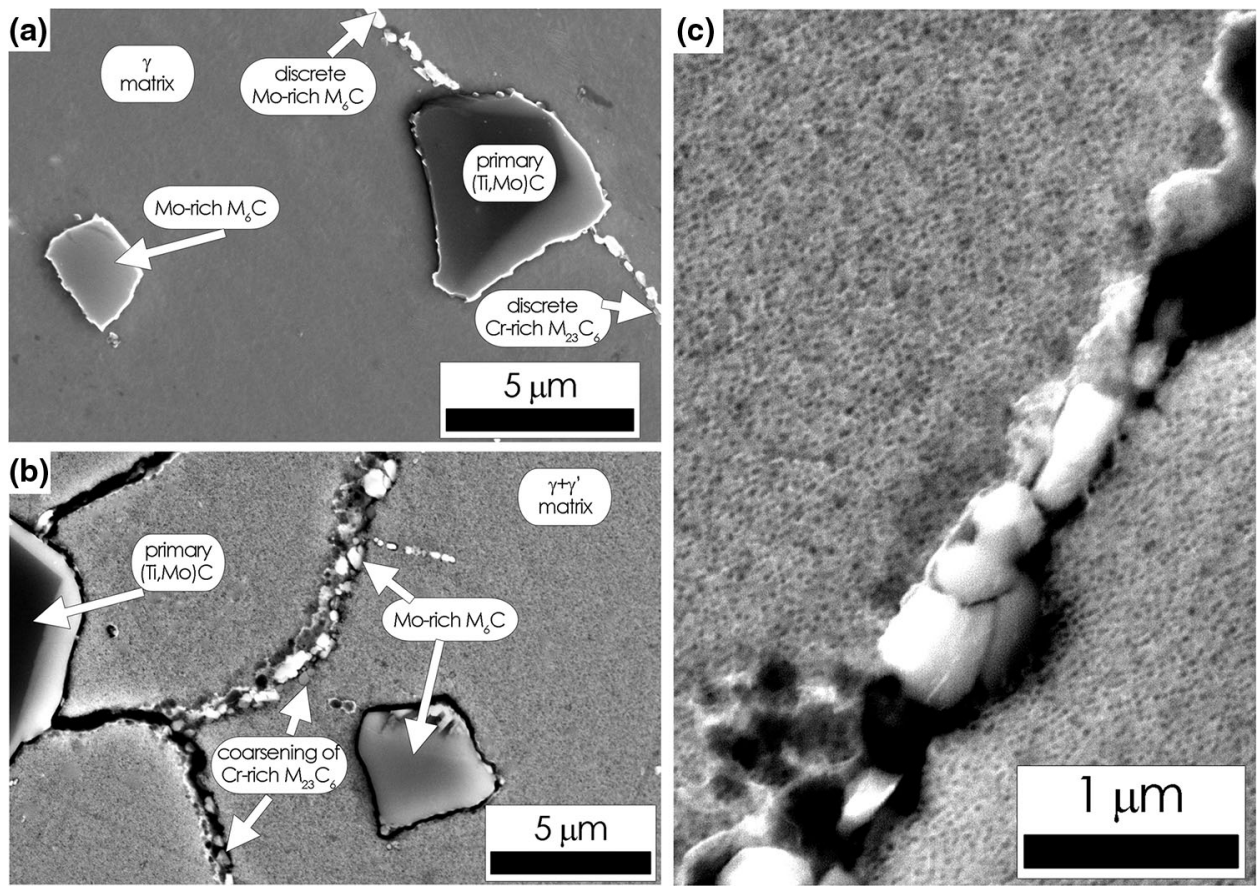

Fig. 3 FEG-SEM images of Haynes 282 alloy after the standard aging treatment: $1010{ }^{\circ} \mathrm{C} / 2 \mathrm{~h}(\mathrm{a})+780{ }^{\circ} \mathrm{C} / 8 \mathrm{~h}$ (b). A high magnification image showing precipitation of nano-size $\gamma^{\prime}$ particles after the second stage of aging at $780{ }^{\circ} \mathrm{C} / 8 \mathrm{~h}$ (c)

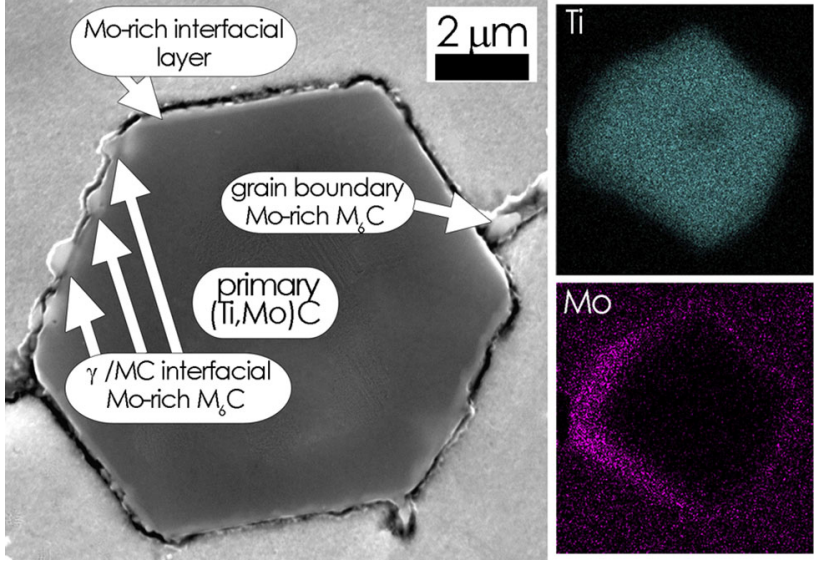

Fig. 4 The FEG-SEM/EDS images of Haynes 282 alloy after the standard aging treatment $1010{ }^{\circ} \mathrm{C} / 2 \mathrm{~h}+780{ }^{\circ} \mathrm{C} / 8 \mathrm{~h}$ showing effects of the reaction taken at the primary $\mathrm{MC} / \gamma$ solid solution interface leading to the formation of Mo-rich outer area and a growth of new $\mathrm{M}_{6} \mathrm{C}$ carbides as interfacial products

$M C+\gamma \rightarrow M_{23} C_{6}+\gamma^{\prime}$

$M C+\gamma \rightarrow M_{6} C+\gamma^{\prime}$

By taking into account the chemical composition of involved phase constituents, the Reactions 1 and 2 might be rewritten as follows, respectively:

$(\mathrm{Ti}, \mathrm{Mo}) C+(\mathrm{Ni}, \mathrm{Cr}, \mathrm{Al}, \mathrm{Ti}) \rightarrow \mathrm{Cr}_{21} \mathrm{Mo}_{2} \mathrm{C}_{6}+\mathrm{Ni}_{3}(\mathrm{Al}, \mathrm{Ti})$

$$
\begin{aligned}
(\mathrm{Ti}, \mathrm{Mo}) C+(\mathrm{Ni}, \mathrm{Co}, \mathrm{Al}, \mathrm{Ti}) \rightarrow & \mathrm{Mo}_{3}(\mathrm{Ni}, \mathrm{Co})_{3} C \\
& +\mathrm{Ni}_{3}(\mathrm{Al}, \mathrm{Ti})
\end{aligned}
$$

As it comes from the results of thermodynamic calculations presented by Yang et al. ( $\operatorname{Ref} 8), \mathrm{M}_{6} \mathrm{C}$ carbides are more thermodynamically stable than $\mathrm{M}_{23} \mathrm{C}_{6}$ at temperatures higher than $780{ }^{\circ} \mathrm{C}$. According to Lvov et al. (Ref 12), Reactions 3 and 4 are based on diffusion mechanism of carbon from the carbon-rich MC carbide to the matrix and the diffusion of $\mathrm{Ni}$, $\mathrm{Cr}$ and $\mathrm{Co}$ in the opposite direction. However, the occurrence of aforementioned transformations strongly depends on macroand micro-segregations of chemical elements (especially a local accumulation of chromium and/or molybdenum), and consequently, both of them might take place at the same annealing conditions.

After the second stage of standard treatment, the hardness was strongly increased as compared to the solution-treated material (from 250 to $373 \mathrm{HV}$ ).

\subsection{Heat Treatments at Extended Temperature Ranges}

3.2.1 The First Stage of Aging Treatment. In this work, the first stage of aging (annealing for $2 \mathrm{~h}$ ) was carried out at: $900,950,1010,1050$ and $1100^{\circ} \mathrm{C}$. Subsequently, for each of these samples, the second stage (annealing for $8 \mathrm{~h}$ ) was performed at: 680, 730, 780, 830 and $880{ }^{\circ} \mathrm{C}$ (Fig. 1a, b).

Firstly, a strong temperature dependence of the first-stage aging on the measured hardness values was documented (Fig. 5a). It was found that as compared to the sample subjected to the standard heat treatment $\left(1010{ }^{\circ} \mathrm{C} / 2 \mathrm{~h}-263\right.$ $\mathrm{HV}$ ), the hardness was either significantly increased (up to 336 $\mathrm{HV}$ ) when the temperature of the first-stage aging was $900{ }^{\circ} \mathrm{C}$; or it was prominently decreased (to $200 \mathrm{HV}$ ), when temperatures of 1050 or $1100{ }^{\circ} \mathrm{C}$ were applied. This observation suggests that the as-received state is actually not fully solution- 



Fig. 5 The effect of temperature of the first-stage aging on the hardness evolution (a) and ASTM grain size (b) in Haynes 282 alloy
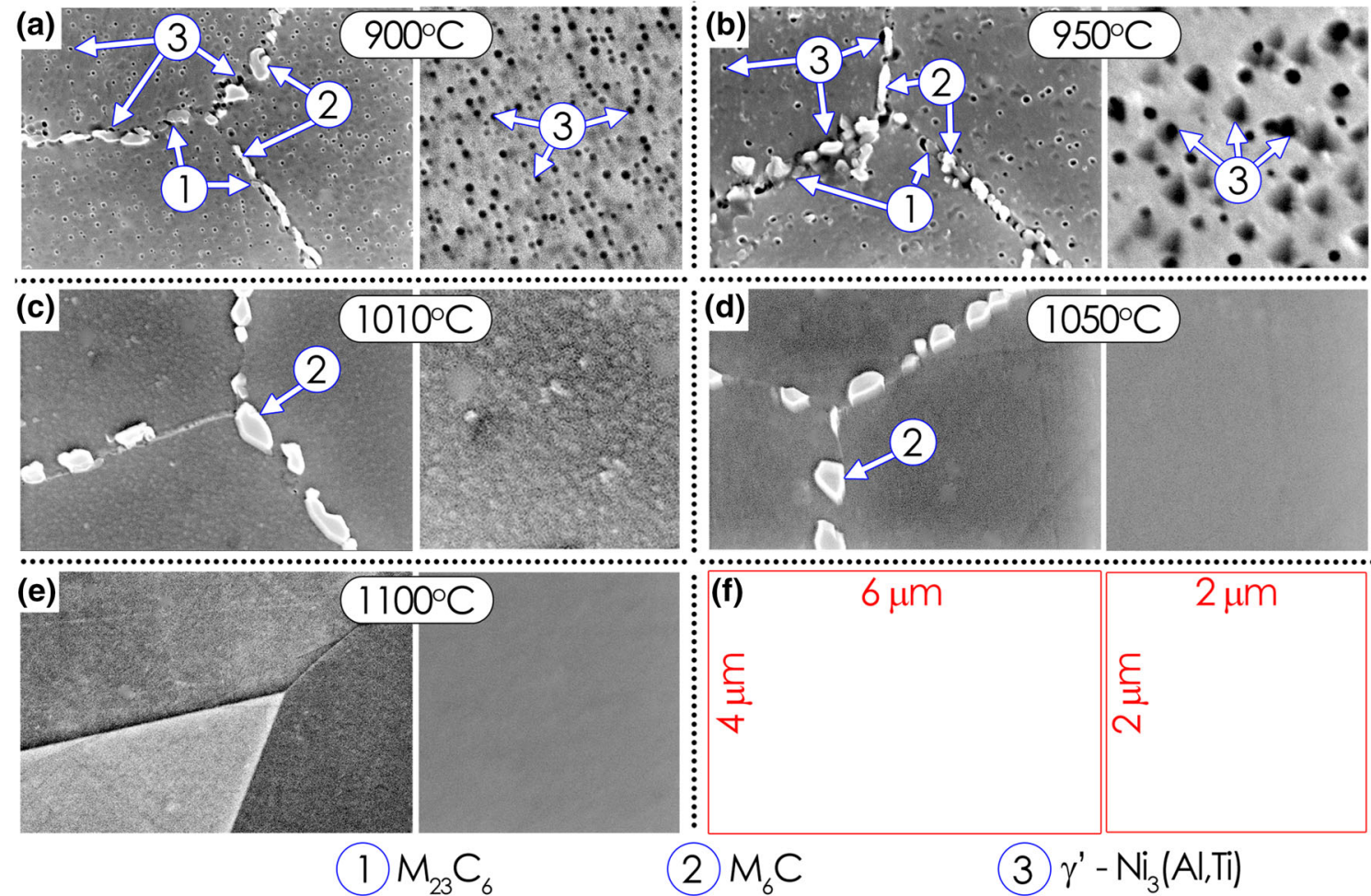

Fig. 6 FEG-SEM images showing structural features in Haynes 282 alloy after the first-stage aging at: $900{ }^{\circ} \mathrm{C} / 2 \mathrm{~h}(\mathrm{a}) ; 950{ }^{\circ} \mathrm{C} / 2 \mathrm{~h}(\mathrm{~b})$;

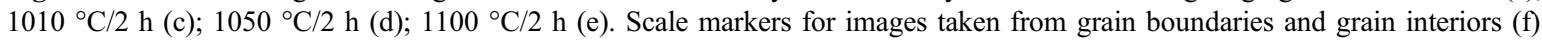

annealed. However, the industrial mill annealing involves air cooling rather than quenching (as it was applied in the present work), resulting in (sub-SEM resolution) gamma prime particles precipitated during cooling. Similar observations have been also made, e.g., by Joseph et al. (Ref 9). Additionally, as it is presented in Fig. 5(b), using of very high temperature of the first-stage aging results in a substantial grain growth (the corresponding grain diameter for the ASTM grain number 0 is $\sim 360 \mu \mathrm{m}$ ) having also a detrimental effect on the room temperature hardness.

The results of detailed structural characterization allow concluding that reasons for such a big difference between hardness of these samples should be related to an evolution of phase composition, dominated by a coarsening and thermal destabilization of grain boundary precipitates with increasing the temperature of the first-stage aging. As it is documented by corresponding SEM images, the highest hardness of the $900{ }^{\circ} \mathrm{C} / 2 \mathrm{~h}$ sample is determined by the high volumetric content of the $\mathrm{Ni}_{3}(\mathrm{Al}, \mathrm{Ti})$ phase precipitates located both intraand intergranularly and by a discrete grain boundary carbides distribution (Fig. 6a). At higher temperatures of the first-stage aging, both carbides and the $\gamma^{\prime}$ phase precipitates were coarsened (at $950{ }^{\circ} \mathrm{C} / 2 \mathrm{~h}$-Fig. 6b), while at $T>1010{ }^{\circ} \mathrm{C}$ (Fig. 6c, $d$ and e), no evidence for the presence of $\gamma^{\prime}$ and $\mathrm{M}_{23} \mathrm{C}_{6}$ phases was detected by the SEM. Accordingly, the $\mathrm{M}_{6} \mathrm{C}$ grain boundaries carbides were found to be more stable, as it was documented by the fact that they were still found in specimens heat-treated at 1010 and $1050{ }^{\circ} \mathrm{C}$. Grain boundaries seemed to 

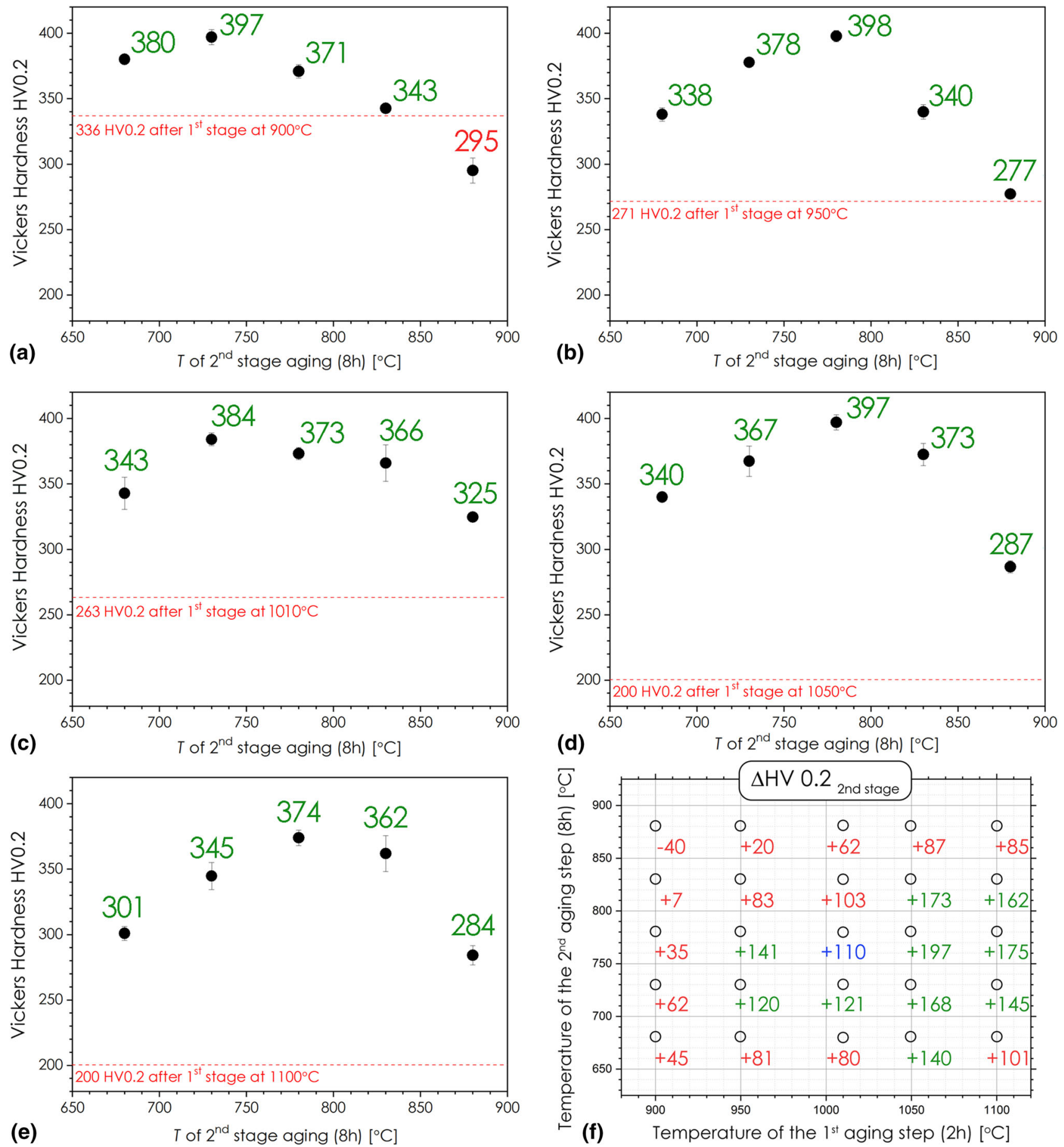

Fig. 7 The effect of temperature of the second-stage aging on microhardness evolution in the specimens annealed in the first stage at: $900{ }^{\circ} \mathrm{C}$ (a); $950{ }^{\circ} \mathrm{C}(\mathrm{b}) ; 1010{ }^{\circ} \mathrm{C} \mathrm{(c);1050}{ }^{\circ} \mathrm{C}(\mathrm{d}) ; 1100{ }^{\circ} \mathrm{C}(\mathrm{e})$. A comparison of hardness increase in the second stage of aging $\left(\Delta \mathrm{HV} \mathrm{V}_{2 \text { nd stage }}\right)-\mathrm{values}$ higher than that for the standard treatment are marked with green color, while lower ones with red color (f) (Color figure online)

be completely "clean" only when temperature of the first stage of aging treatment was as high as $1100{ }^{\circ} \mathrm{C}$ (Fig. 6e). Thus, increasing the temperature of the first-stage treatment allows a more complete dissolution of both primary and secondary precipitates.

These results are in a good agreement with equilibrium phase diagrams for the Haynes 282 alloy presented by Yang et al. (Ref 8) showing that $\mathrm{M}_{23} \mathrm{C}_{6}$, the $\gamma^{\prime}$ and $\mathrm{M}_{6} \mathrm{C}$ phases become unstable at temperatures above 800,1000 and $1080{ }^{\circ} \mathrm{C}$, respectively.

3.2.2 The Second Stage of Aging Treatment. The effect of temperature of the second stage of aging treatment (for $8 \mathrm{~h}$ ) on the hardness evolution is documented in Fig. 7. It is found that independently on applied temperatures of the first stage of aging treatment, the peak strengthening in the second stage took place at $730{ }^{\circ} \mathrm{C}$ (Fig. 7a and c) or $780{ }^{\circ} \mathrm{C}$ (Fig. 7b, d and 


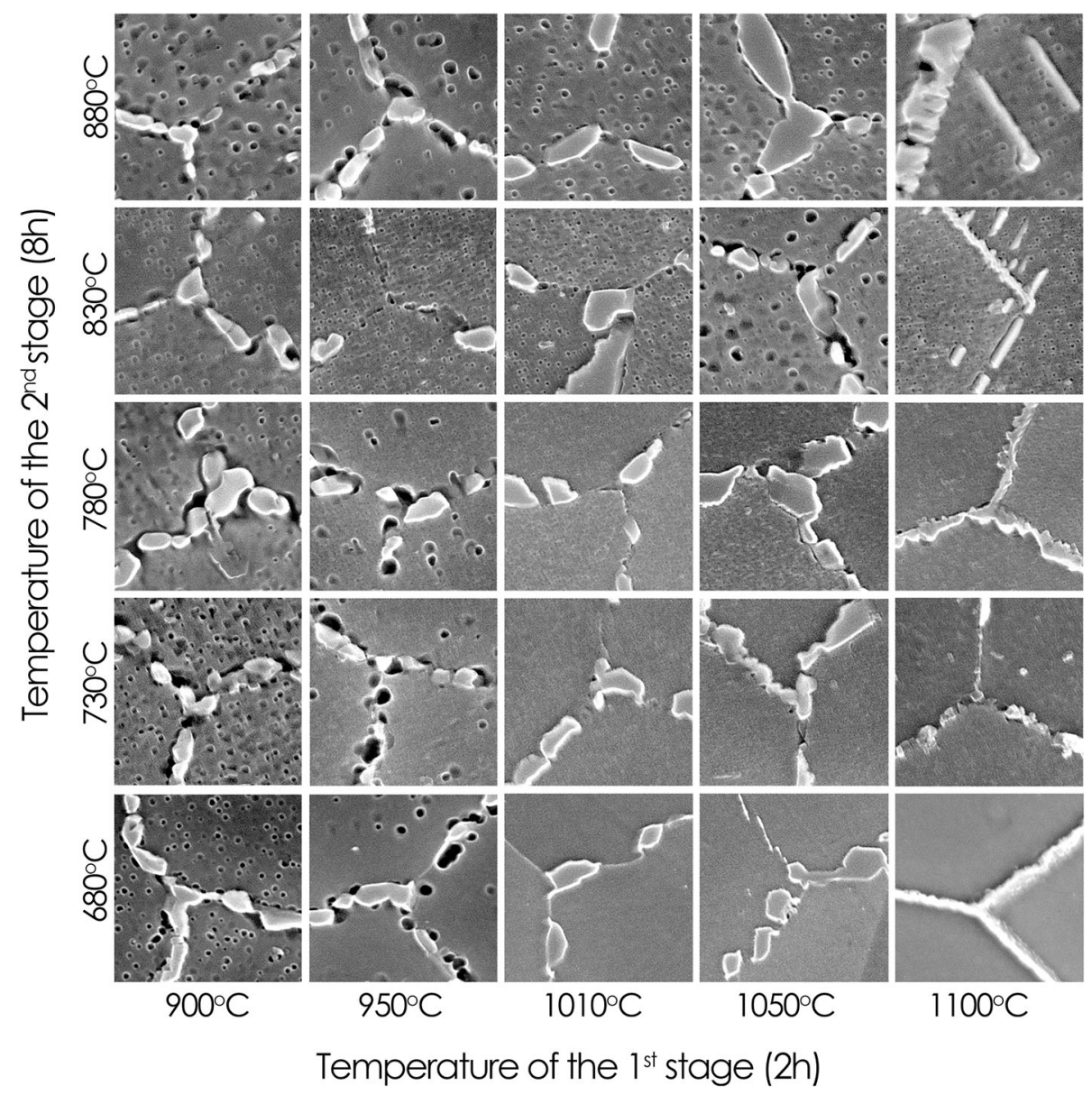

Fig. 8 A set of SEM images showing the $\gamma^{\prime}$ and carbide precipitates evolution upon multi-variant two-stage aging treatment of Haynes 282. Each SEM image was taken from $2 \mu \mathrm{m} \times 2 \mu \mathrm{m}$ area located in a near vicinity of triple points

e) for almost all examined variants. A difference between hardness of samples after the first- and the second-stage treatment ("second-stage strengthening effectiveness," $\Delta \mathrm{HV}_{2 \mathrm{nd}}$ stage) (Fig. 7f) generally increases with raising temperature of the first stage. The highest $\Delta H V_{2 n d}$ stage values were measured for the specimens aged in the first stage at $1050{ }^{\circ} \mathrm{C}$ or $1100{ }^{\circ} \mathrm{C}$, i.e., for these variants in which secondary particles $\left(\gamma^{\prime}\right.$ and $\mathrm{M}_{23} \mathrm{C}_{6}$ carbides) were not previously precipitated. In order to clarify the effect of microstructural features lying behind the measured variations in hardness values, a set of SEM images showing the evolution of the $\gamma^{\prime}$ phase and grain boundary precipitates (Fig. 8) was prepared. It should be noted that the high hardness increase in the second-stage aging carried out at lowered temperatures (i.e., $680{ }^{\circ} \mathrm{C}$ and especially $730{ }^{\circ} \mathrm{C}$ ) should be related to an extremely small size of the precipitated $\gamma^{\prime}$ particles making them almost undetectable for the applied SEM device. Interestingly, for $\left(950{ }^{\circ} \mathrm{C} / 2 \mathrm{~h}+780{ }^{\circ} \mathrm{C} / 8 \mathrm{~h}\right)$ and $\left(1050{ }^{\circ} \mathrm{C} / 2 \mathrm{~h}+830{ }^{\circ} \mathrm{C} / 8 \mathrm{~h}\right)$, bimodal $\gamma^{\prime}$ size distributions were obtained. As it was previously reported by Joseph et al. (Ref 9), this structural feature allows receiving an optimal strength/ductility balance in Haynes 282 alloy, and indeed, also in the present study, the highest hardness of $398 \pm 4 \mathrm{HV}$ was measured for the $\left(950{ }^{\circ} \mathrm{C} / 2 \mathrm{~h}+780{ }^{\circ} \mathrm{C} / 8 \mathrm{~h}\right)$ heat-treated spec-

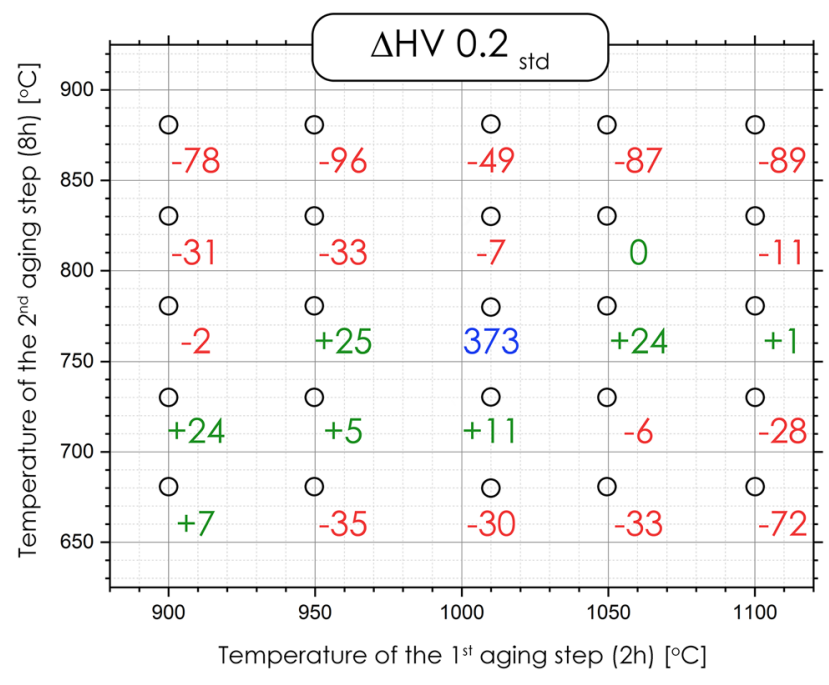

Fig. 9 The effect of applied full heat treatment temperatures on Vickers hardness (as compared to that after standard $1010{ }^{\circ} \mathrm{C} /$ $2 \mathrm{~h}+780^{\circ} \mathrm{C} / 8 \mathrm{~h}$ aging). Values higher than that for the standard treatment are marked with green color, while lower ones with red color (Color figure online) 
imen. However, static tensile tests are planned to further explore the effect of bimodal $\gamma^{\prime}$ size distributions on the mechanical response of the alloy.

Finally, the effect of applied alternative full heat treatments (i.e., composed of two-stage aging at $900-1100{ }^{\circ} \mathrm{C} / 2 \mathrm{~h}$ and 680 $880{ }^{\circ} \mathrm{C} / 8 \mathrm{~h}$ ) on microhardness is illustrated in Fig. 9. It is found that by using various combinations of temperatures of the first and second stage of aging, the room temperature hardness of Haynes 282 alloy can be decreased by $\sim 100 \mathrm{HV}$ units or increased of up to $25 \mathrm{HV}$ units as compared to that of the alloy subjected to the standard heat treatment schedule. Such a high hardness variation should be justified in terms of complex structural evolution involving the secondary precipitation of $\gamma^{\prime}, \mathrm{M}_{23} \mathrm{C}_{6}$ and $\mathrm{M}_{6} \mathrm{C}$ phases as well as their interaction with the fcc $\gamma$ matrix.

\section{Summary and Conclusions}

The results of microstructural characterization revealed following effects of altering temperatures of the standard heat treatment $\left(1010{ }^{\circ} \mathrm{C} / 2 \mathrm{~h}+780{ }^{\circ} \mathrm{C} / 8 \mathrm{~h}\right)$ of Haynes 282 alloy:

(1) lowering of the first-stage aging temperature to $950{ }^{\circ} \mathrm{C}$ and $900{ }^{\circ} \mathrm{C}$ resulted in a precipitation of $\gamma^{\prime}$ particles responsible for a relatively high hardness. On the other hand, using the standard $\left(1010{ }^{\circ} \mathrm{C} / 2 \mathrm{~h}\right)$ or increased temperatures $\left(1050{ }^{\circ} \mathrm{C} / 2 \mathrm{~h}\right.$ or $\left.1100{ }^{\circ} \mathrm{C} / 2 \mathrm{~h}\right)$ thermally destabilizes both $\gamma^{\prime}$ and carbides strengthening precipitates. It is also worth noting that $\mathrm{M}_{6} \mathrm{C}$-type carbides confirmed their highest thermal stability. Nevertheless, special attention should be paid to $\left(950{ }^{\circ} \mathrm{C} /\right.$ $2 \mathrm{~h}+780^{\circ} \mathrm{C} / 8 \mathrm{~h}$ ) treatment giving the bimodal $\gamma^{\prime}$ size distribution and the highest average hardness.

(2) using of the lowered temperature of the second-stage aging $\left(730{ }^{\circ} \mathrm{C} / 8 \mathrm{~h}\right)$ gives a precipitation of extremely fine (almost undetectable by SEM) $\gamma^{\prime}$ particles that increased the final material's hardness.

The future work will focus on the effect of applied heat treatments on tensile properties of the Haynes 282 alloy as well as on more detailed microstructural studies (involving high resolution transmission electron microscopy) of the $\gamma^{\prime}$ evolution. What should be also noted is the fact that Haynes 282 alloy is supposed to be used at elevated temperatures and a high hardness values obtained at room temperature do not necessarily equate to an ideal condition for service. Therefore, more studies on stability of structure (and hardness) produced through the proposed heat treatments under predicted service conditions are still needed.

\section{Acknowledgments}

Financial support from the Polish National Science Centre under Grant no. UMO-2016/23/D/ST8/01269 (SONATA 12) is gratefully acknowledged. Authors are thankful to Mr. Philip J. Maziasz (Energy Industries of Ohio/Oak Ridge National Laboratory, USA) and Mr. Horst Hack (Electric Power Research Institute, USA) for valuable suggestions and comments to the paper.

\section{Open Access}

This article is distributed under the terms of the Creative Commons Attribution 4.0 International License (http://creativecommons.org/ licenses/by/4.0/), which permits unrestricted use, distribution, and reproduction in any medium, provided you give appropriate credit to the original author(s) and the source, provide a link to the Creative Commons license, and indicate if changes were made.

\section{References}

1. Superalloys Market - Global Industry Analysis, Size, Share, Growth, Trends and Forecast 2017-2025. https://www.transparencymarketresea rch.com/superalloys-market.html. Accessed 06 Aug 2018

2. L.M. Pike, Haynes ${ }^{\circledR} 282 \AA$ alloy-a new wrought superalloy designed for improved creep strength and formability, in Proceedings of ASME Tubo Expo 2006, Power for Land, Sea and Air, pp. 1031-1039

3. K.L. Kruger, HAYNES 282 alloy, Materials for ultra-supercritical and advanced ultra-supercritical power plants, A. Di Gianfrancesco, Ed., Woodhead Publishing, Elsevier, Sawston, 2017, p 511545

4. Y.-J. Kim, J.-H. Park, Y.-S. Ahn, Comparison of Creep Properties of Cast and Wrought Haynes 282 Superalloy. Adv. Mater. Sci. Eng. Article ID 2048959 (2018). https://doi.org/10.1155/2018/2048959

5. H. Matysiak, M. Zagorska, J. Andersson, A. Balkowiec, R. Cygan, M. Rasinski, M. Pisarek, M. Andrzejczuk, K. Kubiak, and K.J. Kurzydlowski, Microstructure of Haynes $\AA 282 \AA$ Superalloy after Vacuum Induction Melting and Investment Casting of Thin-Walled Components, Materials, 2013, 6, p 5016-5037

6. L.M. Pike, Development of a fabricable gamma-prime $\left(\gamma^{\prime}\right)$ strengthened superalloy, in Proceedings of 11th International Symposium Superalloy 2008, Champion, PA, USA, September 2008, TMS, pp. 191-200

7. L.O. Osoba, A.K. Khan, and O.A. Ojo, Identification of Mo-based Precipitates in Haynes 282 Superalloy, Metall. Mater. Trans. A, 2017, 48, p 1540-1543

8. Y. Yang, R.C. Thomson, R.M. Leese, S. Roberts, Microstructural evolution in cast Haynes 282 for application in advanced power plants, in D. Gandy, J. Shingledecker (eds.), Advances in Materials Technology for Fossil Power Plants, Proceedings of the 7th International Conference (EPRI 2013), October 2013, Waikoloa, Hawaii, USA. ASM International, pp. 143-154

9. C. Joseph, C. Persson, and M.H. Colliander, Influence of Heat Treatment on the Microstructure and Tensile Properties of Ni-base Superalloy Haynes 282, Mater. Sci. Eng. A, 2017, 679, p 520-530

10. S. Haas, J. Andersson, M. Fisk, J.-S. Park, and U. Lienert, Correlation of precipitate evolution with Vickers hardness in Haynes ${ }^{\circledR} 282 \AA$ superalloy: In-situ high-energy SAXS/WAXS investigation, Mater. Sci. Eng. A, 2018, 711, p 250-258

11. N. El-Bagoury, Ni Based Superalloys: Casting Technology, Metallurgy, Development, Properties and Applications, Int. J. Eng. Sci. Res. Technol., 2016, 5, p 108-152

12. G. Lvov, V.I. Levit, and M.J. Kaufman, Mechanism of Primary MC Carbide Decomposition in Ni-Base Superalloys, Metall. Mater. Trans. $A, 2004,35$, p 1669-1679 